Revista Destaques Acadêmicos, Lajeado, v. 12, n. 2, 2020. ISSN 2176-3070

DOI: http://dx.doi.org/10.22410/issn.2176-3070.v12i2a2020.2612

http://www.univates.br/revistas

\title{
EDUCAÇÃO FÍSICA NO ENSINO MÉDIO: DIÁLOGOS COM ESTUDANTES SOBRE O DESINTERESSE PELAS EXPERIMENTAÇÕES CORPORAIS
}

\author{
Wellington Kupka Claus ${ }^{1}$, Leandro Oliveira Rocha ${ }^{2}$
}

\begin{abstract}
Resumo: Esta pesquisa, um trabalho de conclusão de curso, discute o desinteresse dos estudantes do Ensino Médio pelas experimentações corporais nas aulas de Educação Física. $\mathrm{O}$ tema e sua delimitação emergem das experiências docentes na disciplina de estágio supervisionado no Ensino Médio, marcadas por tensionamentos com estudantes que se negavam em participar das atividades práticas. Metodologicamente, trata-se de uma pesquisa qualitativa realizada em uma escola pública estadual, cujas informações foram coletadas por meio de observações de aulas e entrevistas semiestruturadas com cinco participantes: quatro estudantes do $3^{\circ}$ ano do Ensino Médio e a professora de Educação Física da turma. Em conclusão, foi identificado que o desinteresse dos estudantes está condicionado ao descompasso entre o que é planejado e desenvolvido nas aulas e as suas expectativas e percepções sobre a Educação Física. Por conseguinte, a pesquisa revela a permanência de uma perspectiva reducionista sobre a função educativa da Educação Física e destaca a importância de pesquisas na escola.
\end{abstract}

Palavras-chave: Educação Física escolar; Ensino Médio; Pesquisa qualitativa.

\section{INTRODUÇÃO}

Este texto, oriundo de um trabalho de conclusão do curso de Educação Física Licenciatura da Universidade do Vale do Taquari - Univates, tematiza a Educação Física no Ensino Médio e apresenta diálogos com estudantes de uma escola pública estadual para discutir a seguinte questão de pesquisa: $O$ que mobiliza o desinteresse dos estudantes do Ensino Médio pelas experimentações corporais nas aulas de Educação Física?

A opção pelo tema, sua delimitação e a proposta de dialogar com os estudantes emerge das experiências docentes durante a disciplina de Estágio

1 Graduado em Educação Física Licenciatura, Universidade do Vale do Taquari.

2 Doutor em Ciências do Movimento Humano, Universidade Federal do Rio Grande do Sul; Professor da Universidade do Vale do Taquari. 
Supervisionado III - Educação Física no Ensino Médio, que foram marcadas por dificuldades e tentativas frustradas de mobilizar a participação dos estudantes nas experimentações corporais desenvolvidas nas aulas. Para compreender melhor, os estudantes simplesmente sentavam nas arquibancadas ao entrar no ginásio ou abandonavam as atividades práticas sem qualquer motivo aparente ou argumento plausível, em ambos os casos permanecendo alheios às práticas pedagógicas e aos apelos da professora de Educação Física titular para aderir, pelo menos, aos diálogos coletivos geralmente realizado no início e no fim da aula.

Naturalmente, o período do estágio supervisionado foi carregado de dúvidas e diversas aprendizagens fundamentais para formação de professor, principalmente porque integrou a observação de aulas na escola onde o estágio foi realizado, a qual é conveniada com o Curso de Educação Física da Univates, a elaboração da proposta pedagógica para as turmas observadas e, na sequência, a prática docente visando contemplar os conteúdos de ensino da Educação Física e a problematização do trabalho docente. Todavia, são os tensionamentos com os estudantes que suscitaram a busca por compreender melhor o porquê da recusa deliberada em participar das experimentações corporais, algo que, segundo a professora de Educação Física, era frequente nas turmas dos três anos do Ensino Médio desta escola.

Por isso retornamos à escola, agora na condição de pesquisadores, para dialogar com os estudantes do Ensino Médio sobre o que motiva ou desmotiva em participar das experimentações corporais e o que aprenderam nas aulas de Educação Física. No que segue às respostas obtidas, foi possível identificar a presença de equívocos sobre a finalidade e a potencialidade educativa da Educação Física, algo que discutiremos na análise das informações, intitulada neste texto de forma interrogativa: "o desinteresse indica uma visão limitada da Educação Física escolar?", apresentada logo após a descrição dos procedimentos metodológicos e anterior as considerações finais - onde destacamos a importância de reforçar a legitimidade da Educação Física na escola.

\section{PROCEDIMENTOS METODOLÓGICOS}

Esta pesquisa qualitativa descritiva contém informações coletadas na escola para discutir e analisar a Educação Física no Ensino Médio. Diferente da mera busca por opiniões de informantes, prima pela descoberta de códigos sociais a partir de falas e símbolos para problematizar a própria sociedade (MINAYO, 2007), visto que, na pesquisa qualitativa, o investigador é o principal agente na coleta de informações e seu interesse primordial está na possibilidade de produzir interpretações com o propósito de compreender o significado que os participantes da pesquisa atribuem às suas experiências (BOGDAN; BIKLEN, 1994). 
Conforme identificado introdutoriamente, a investigação foi realizada na escola pública estadual, localizada no município de Encantado/RS, onde desenvolvemos as atividades de Estágio Supervisionado III - Ensino Médio. Inicialmente, a pesquisa foi devidamente autorizada pelo responsável da Coordenadoria Regional de Educação e pelo diretor da escola, por meio da assinatura na Carta de Anuência. Em seguida as informações foram coletadas por meio de duas observações de aulas e cinco entrevistas semiestruturadas, as quais ocorreram na escola em horário previamente agendado com cada participante, foram gravadas em áudios, transcritas, validadas e consentidas em compor a pesquisa por meio da assinatura dos entrevistados no Termo de Consentimento Livre e Esclarecido e no Termo de Assentimento (assinado pelos responsáveis dos estudantes menores de 18 anos de idade). Desde já é importante esclarecer que os nomes utilizados para identificar os cinco participantes da pesquisa são fictícios, visando preservar o sigilo de suas identidades.

Constituindo a primeira etapa da coleta de informações, foram observadas duas aulas de Educação Física para registar as práticas pedagógicas desenvolvidas e a participação dos estudantes, obviamente com o intuito de também identificar os estudantes que participariam da pesquisa. Nestas observações foram anotados os nomes dos estudantes que demonstravam comprometimento com a proposta da aula e daqueles que permaneciam alheios às atividades, o que em seguida, e com o auxílio da professora Paula-professora de Educação Física da turma e participante da pesquisa -, possibilitou selecionar os quatro estudantes que participaram da pesquisa, uma menina e um menino que participam das aulas e uma menina e um menino que não participam. Nesse caso, Antônio e Ana que demonstravam disponibilidade corporal nas aulas, embora, às vezes, reclamassem e abandonassem temporariamente as atividades quando estas lhes desagradavam, e Pedro e Maria, que explicitamente preferiam não participar das experimentações corporais, exceto nas atividades aparentemente divertidas ou quando sucumbiam aos convites incessantes dos colegas.

Sobre a análise das informações, é importante destacar a potencialidade da entrevista semiestruturada na pesquisa qualitativa, cuja obra de Chemin (2015) sintetiza a entrevista como técnica de obtenção de informações instantâneas, realizada de forma presencial ou a distância (telefone, videoconferência), e estudos, como de Triviños (1987), enfatizam o caráter semiestruturado como um diálogo entre entrevistador e entrevistado a partir de um roteiro de perguntas abertas, que pode ser reorganizado durante a entrevista e geralmente está apoiado em perspectivas teóricas e hipóteses relacionadas ao tema da investigação. Logo, as informações coletadas nas entrevistas passam a constituir o material textual que sustenta as análises de pesquisa, que integra o processo de "descrevê-lo e interpretá-los no sentido de 
atingir uma compreensão mais elaborada dos fenômenos e dos discursos no interior dos quais foram produzidos" (MORAES, 2007, p.89).

\section{O DESINTERESSE INDICA UMA VISÃO LIMITADA DA EDUCAÇÃO FÍSICA ESCOLAR?}

Na reflexão sobre as aulas de Educação Física ao longo do Ensino Médio, os quatro estudantes destacam a continuidade das mesmas às modalidades esportivas, basicamente futsal e voleibol, e situações que motivam ou desmotivam a participar das atividades propostas pelos professores, como é possível identificar no diálogo com a estudante Ana:

Pesquisador: Como foram as tuas aulas de Educação Física durante os três anos do Ensino Médio?

Ana: Ao longo dos três anos foram as mesmas coisas, o que mudou foi quando veio os estagiários e nos mostraram coisas novas. Acho que não seguiam a linha de trabalho da professora titular.

Pesquisador: $\mathrm{O}$ que te motiva em participar das aulas?

Ana: Motiva o trabalho em grupo, todo mundo ligado, ajudando um ao outro.

Pesquisador: E o que desmotiva?

Ana: Desmotiva quando a gente erra e, às vezes, eles [a turma] ficam reclamando, te botando pra baixo (Entrevista com Ana).

Com argumento diferente, porém desfecho semelhante, Maria entende que o desenvolvimento das mesmas práticas corporais durante o ano letivo torna as aulas de Educação Física nada atraentes e, portanto, muito desmotivadoras. Conforme registrado:

Pesquisador: Como foram as aulas de Educação Física durante o Ensino Médio?

Maria: A professora só dá vôlei e futsal, como não gosto desses esportes, não participo.

Pesquisador: O que te motiva em participar das aulas?

Maria: Nada me motiva e nada me desmotiva. Não participo.

Pesquisador: Como assim? Nada desperta o teu interesse em participar?

Maria: Sei lá. Eu jogo somente quando realmente precisa, pra ter nota, e no inverno não participo porque é muito frio, os dedos congelam e dói ficar jogando bola.

Pesquisador: E se a aula fosse de alguma outra prática corporal, que não envolvesse bola, será que chamariam a tua atenção?

Maria: Olha, se a professora desse a dança ou alguma coisa assim, talvez eu me motivaria.

Pesquisador: Então o teu desinteresse está relacionado com as atividades, propostas, isso? 
Maria: Isso, é que é sempre vôlei e futebol, sempre intercalando esses dois esportes. São coisas que a gente sabe desde criança, aí desmotiva (Entrevista com Maria).

Mesmo considerando as críticas contundentes à pouca variedade de práticas corporais desenvolvidas nas aulas de Educação Física e o modo como os jogos geram insatisfações, é importante destacar a visão de Pedro, que diferente das duas meninas não reclama em praticar as mesmas modalidades esportivas. Para ele, um entusiasta da modalidade de futsal, todas as aulas de Educação Física deveriam ser destinadas para jogar futsal, por isso não participa de outras atividades, somente do momento do jogo. Com relação a sua motivação Pedro assim destaca:

Pedro: Só gosto de jogar futsal.

Pesquisador: Mas o que te motiva a participar das aulas?

Pedro: Quando estou jogando bem.

Pesquisador: Quando sabe bem o esporte?

Pedro: Sim.

Pesquisador: E o que desmotiva?

Pedro: Quando o cara não sabe ou não tá muito bem no jogo.

Pesquisador: Quando você diz "o cara", refere-se a você ou aos colegas?

Pedro: A mim, quando não estou jogando bem o esporte (Entrevista com Pedro).

Se a motivação de Pedro está condicionada ao seu próprio desempenho durante os jogos de futsal, Antônio, por sua vez, considera a falta de comprometimento dos colegas em aprender os jogos e a necessidade de aprofundar aprendizagens sobre os esportes como principal problema das aulas, algo que assim evidenciou na entrevista:

Pesquisador: O que você aprendeu nas aulas de Educação Física ao longo do Ensino Médio?

Antônio: Basicamente só aprendi vôlei e futsal, onde no $1^{\circ}$ ano tinha aula teórica e prática e nos demais anos somente a prática propriamente dita.

Pesquisador: O que te motiva nas aulas de Educação Física?

Antônio: Motiva sempre querer mais, aprender mais. Você gosta daquilo e tu quer mais, quer sempre melhorar, mesmo os períodos sendo curto tento dar o máximo possível.

Pesquisador: E o que te desmotiva?

Antônio: Falta de interesse dos alunos, que só vão na aula para estragar (Entrevista com Antônio).

Para Antônio a falta de diversificação das aulas não é problema, pois aprecia qualquer modalidade esportiva. Ademais, segundo ele, a principal 
diferença que ocorreu ao longo dos três anos no Ensino Médio foi a ênfase atribuída ao ensino de regras oficiais e fundamentos técnicos básicos dos esportes coletivos no $1^{\circ}$ ano do Ensino Médio, inclusive por meio de aulas expositivas em sala de aula, que lembra com entusiasmo porque entende que agregou muitos conhecimentos. No entanto, igualmente relatado pelos demais estudantes, pouco foi alterado nos dois anos seguintes, cuja maior diversificação de práticas corporais é decorrente da prática docente de estagiário de cursos de graduação em Educação Física.

Se por um lado a diversificação das práticas corporais parece ambígua para determinar a adesão ou o abandono dos estudantes nas atividades desenvolvidas e a motivação em participar também está condicionada às situações que ocorrem no momento da aula, de outro lado há um comum descontentamento com a forma de seleção das práticas corporais, que são estabelecida exclusivamente pela professora, sem contemplar os seus gostos e interesses pessoais. Trata-se de um aspecto que relacionamos com o estudo de Ferreira, Graebner e Matias (2014), cuja adesão dos estudantes de Ensino Médio, nas aulas de Educação Física, estava diretamente relacionada à sensação de divertimento ou à necessidade de participar das atividades para receber a nota do trimestral (FERREIRA; GRAEBNER; MATIAS, 2014). Não obstante, segundo Ferreira, Graebner e Matias (2014), o principal motivo do desinteresse dos estudantes pelas aulas de Educação Física também estava diretamente relacionado ao fato dos conteúdos de ensino serem selecionados exclusivamente pelo professor, os quais, por vezes, não tinham qualquer sentido em suas vidas fora da escola.

Dado exposto, entendemos que os estudantes clamam por participação nas tomadas de decisões, algo que parece ser desconsiderado ou não percebido pela professora e leva-os a rechaçar seus esforços e reclamar de seus procedimentos metodológicos de ensino. Por conseguinte, a relação de conflitos entre estudantes e professora parecem se estender a muito tempo, conforme identificado pela professora Paula e comumente observável em estudo da área da Educação Física escolar, sobretudo nas pesquisas que enfatizam a importância de refletir sobre os conteúdos e as metodologias de ensino utilizadas pelos professores na tentativa de mobilizar maior adesão e sentido às aulas de Educação Física no Ensino Médio (CELANTE, 2000; CHICATI, 2000; FERREIRA; GRAEBNER; MATIAS, 2014; LIMA FILHO, 2016; ALMEIDA; CAUDURO, 2016). Tal como sugere estudos dessa temática, a pluralidade das manifestações culturais corporais é grande aliada dos professores Educação Física, visto que:

Para facilitar a adesão dos alunos às práticas corporais seria importante diversificar as vivências experimentadas nas aulas para além dos esportes tradicionais (futebol, vôlei ou basquetebol). $\mathrm{Na}$ verdade, a inclusão e a possibilidade das vivências das ginásticas, dos jogos, das brincadeiras, das lutas, das danças podem facilitar a 
adesão do aluno na medida em que aumentam as chances de uma possível identificação (DARIDO; SOUZA JÚNIOR, 2007, p. 18).

Por isso seria um equívoco apenas culpabilizar os estudantes pela falta de interesse demonstrado nas aulas sem considerar os motivos que levam ao abandono das experimentações corporais e o sentido das práticas corporais desenvolvidas. Conforme explicado por Zilberstein (2016), a aula de Educação Física que é atraente para os professores talvez não seja atrativa nem tenha sentido para os estudantes, pois, muitas vezes:

Eles [os estudantes] não entendem o objetivo da atividade que estão realizando para além de uma brincadeira e reclamam de estarem atendendo aos pedidos dos professores e não estarem sendo atendidos em seus interesses. Interpreto que esse conflito se dá por conta dos estudantes não estarem sendo vistos como partícipes do processo de ensino-aprendizagem, pois eles manifestam seus interesses, suas necessidades, mas nem sempre o professor consegue enxergar isso (ZILBERSTEIN, 2016, p. 103).

Tal consideração sugere "reconhecer que a educação escolarizada está umedecida de cultura e, em se tratando dos alunos do Ensino Médio, da cultura jovem, implica reconhecer as práticas que são significativas a eles" (SOUZA, 2010, p. 184). Assim como, reforça o diálogo como principal estratégia de ensino para identificar práticas corporais circunscritas na cultura compartilhada pelos estudantes e, por conseguinte, conferir sentido à experimentação prática para problematizar seus significados sociais (LIMA FILHO, 2016).

Mas essas advertências não implicam em questionar a relevância dos conteúdos de ensino ou ampliar o campo de conhecimento da Educação Física, uma vez que apenas consolidam a necessidade de contemplar os saberes da área através de práticas corporais identificadas e selecionadas coletivamente com as turmas, isto é, reconhecendo os estudantes no processo. Conforme indicam de Betti e Zuliani (2002), cabe aos próprios professores de Educação Física a tarefa de dar sentido à sua área de conhecimento na escola, o que não significa uma limitação do trabalho desenvolvido na escola, mas sim, pressupõe que a comunidade escolar geralmente não tem clareza da potencialidade educativa da Educação Física, principalmente no que se refere à sua relação com função social da escola. Explicam os autores:

Nesses tempos de rápidas e profundas transformações sociais que repercutem, às vezes de maneira dramática, nas escolas, a Educação Física e seus professores precisam fundamentar-se teoricamente para justificar à comunidade escolar e à própria sociedade o que já sabem fazer, e, estreitando as relações entre teoria e prática pedagógica, inovar, quer dizer, experimentar novos modelos, estratégias, metodologias, conteúdos, para que a Educação Física 
siga contribuindo para a formação integral das crianças e jovens e para a apropriação crítica da cultura contemporânea (BETTI; ZULIANI, 2002, p. 80).

Nesta análise, o desinteresse dos estudantes não pode ser entendido como mera preguiça, aversão às experimentações corporais ou indiferença aos esforços dos professores. Tampouco endossamos que as aulas de Educação Física precisam agradar a todos os estudantes, algo objetivamente impossível se observar os seus interesses diversos e contrários. De outro modo, entendemos que o desinteresse dos estudantes indica a falta de diálogo somada às dúvidas sobre a relevância da Educação Física escolar. Pensamos assim em função das considerações dos estudantes sobre as aprendizagens construídas na Educação Física e sua finalidade na escola, cuja dúvida, o silêncio e as respostas curtas sejam elas evasivas ou simplificadoras - mostraram-se tão impactantes quanto as críticas estabelecidas sobre as aulas porque, em linhas gerais, colocavam em xeque a função educativa da Educação Física escolar.

Para explicar o que acontece, o estudante Pedro, por exemplo, depois de muito pensar diz que aprendeu a praticar esportes, inclusive gestos técnicos e regras oficiais, nas aulas expositivas realizadas no $1^{\circ}$ ano do Ensino Médio, quando a professora introduziu as modalidades esportiva contempladas nos jogos escolares. Por fim, relutando em responder, ele acredita que a Educação Física na escola é importante para "motivar os alunos a fazer as atividades físicas" (Entrevista com Pedro). A estudante Maria também reafirma a presença marcante dos esportes com exceção de algumas aulas expositivas, nas quais, segundo ela: "aprendi a cuidar do corpo e da saúde, mas nunca teve algo aprofundado sobre um assunto, só teve uma ou duas aulas sobre alimentos", e por isso acredita que "a Educação Física trabalha o corpo, aquecer, desinibição e trabalho em grupo" (Entrevista com Maria).

Depois de um longo tempo para responder, Ana e Antônio demonstram convicção sobre o que se aprenderam nas aulas de Educação Física e sobre a sua finalidade na escola. Segundo Ana: "aprendi a diferença entre atividade física e exercício físico, a Educação Física é importante para a saúde; é que a juventude não dá bola para o esporte, por isso vem aqui na escola para participar e praticar o que não tem tempo de fazer em casa" (Entrevista com Ana). Por sua vez, Antônio entende que aprendeu a jogar melhor os esportes, "a socializar com os colegas, a dialogar e fazer trabalho em grupo e a conhecer os seus limites e o dos colegas" (Entrevista com Antônio), isto é, conhecer suas próprias limitações técnicas e relativas a aptidão física. Em seguida ele finaliza sua fala afirmando que: "a Educação Física serve para sair da monotonia de só aula, aula, aula; além do recreio, é um espaço que tem para o lazer, para praticar esportes e exercícios físicos e não ficar só presos em uma classe, na sala de aula o tempo todo" (Entrevista com Antônio). 
De todas as respostas apresentadas pelos estudantes, a de Antônio é altamente significativa porque sintetiza claramente o entendimento da aula de Educação Física como momento de lazer, de mera fruição, como um tipo de recreio com horário estendido que é destinado para promover a interação social entre os estudantes e aliviar a tensão e a monotonia oriunda das horas continuas de estudo em sala de aula. Em linguagem popular, as aulas de Educação Física serviriam para os estudantes do Ensino Médio "dar um tempo para a cabeça". A situação fica mais preocupante quando o discurso no qual a aula de Educação Física compreende um momento de praticar atividades física é validado pelos próprios professores de Educação Física, o que parece ocorrer nesta escola. Basta observar a resposta da resposta da professora Paula sobre a importância da Educação Física:

A importância, na verdade, é a atividade física. Ela é pra vida toda. A gente tem que ter o hábito de fazer atividades físicas porque sabe que isso é saudável, faz muito bem para o corpo e para mente. [...] É como eu digo para eles: "Pessoal, vocês têm que jogar, vocês têm que participar pela experiência. [...] Quando vocês saírem da escola não terão mais esse vínculo com o esporte" (Entrevista com a professora Paula).

Ao analisar essas respostas, entendemos que a visão dos estudantes está condicionada pela ênfase que a professora Paula atribui à necessidade da prática regular de atividades físicas. Isso não significa que esta professora compreenda a Educação Física somente desta forma simplificada, mas indica a uniformidade e manutenção do discurso reducionista que desconsidera os avanços acadêmicos historicamente produzidos na área de conhecimento da Educação Física; assim como o viés crítico e reflexivo inerente ao termo "cultura corporal", que atualmente é compreendido como objeto de estudo da Educação Física escolar (SOARES et al, 2012). Sobre essa colocação, cabe destacar:

Na perspectiva da reflexão sobre a cultura corporal, a dinâmica curricular, no âmbito da Educação Física, tem características bem diferenciadas das da tendência anterior. Busca desenvolver uma reflexão pedagógica sobre o acervo de formas de representação do mundo que o homem tem produzido no decorrer da história, exteriorizadas pela expressão corporal: jogos, danças, lutas, exercícios ginásticos, esporte, malabarismo, contorcionismo, mímica e outros, que podem ser identificados como formas de representação simbólica de realidades vividas pelo homem, historicamente criadas e culturalmente desenvolvidas (SOARES et al., 2012, p. 39).

Como área de conhecimento que tematiza a cultura corporal, a Educação Física tem a responsabilidade de contribuir na formação de pessoas capazes de se posicionarem criticamente frente à diversos temas, tais como: esporte- 
espetáculo, atividades físicas e consumo, relações de gênero no universo fitness, qualidade de vida ou estética corporal, influências dos meios de comunicação na reprodução cultural da hegemonia dos esportes, ambiguidade na relação entre atividades físicas e promoção de saúde, diferentes representações sociais das manifestações corporais, dentre tantos outros (BETTI; ZULIANI, 2002). Não obstante, a problematização do campo pedagógico da Educação Física escolar vai de encontro com a superação de modelos de ensino tradicionais da Educação Física, marcados pela mera prática de atividades físicas com um fim em si mesmas, isto é, desprovidas de reflexão ou intencionalidade pedagógicas que transcenda o aprendizado de gestos técnicos ou gasto calórico durante a aula.

Por isso não é coerente tentar atrair os estudantes com modalidades esportivas já conhecidas e jogo tradicionais, uma vez que o desafio do professor está em reconsiderar as práticas pedagógicas para ampliar e aprofundar a construção coletiva do conhecimento, o que implica em utilizar metodologias de ensino diversificadas, problematizar situações vividas na contemporaneidade e permitir que o estudante seja agente ativo na construção das aulas (MATTOS; NEIRA, 2000). Conforme já advertira Neira (2010, p. 10): “a simples inclusão das atividades motoras no currículo não representa dignamente a tarefa educacional do componente [porque] a Educação Física tem de proporcionar algo aos alunos que lhes permita superar o saber construído e vivido para além dos muros escolares".

Naturalmente, "cabe ao professor de Educação Física problematizar, interpretar, relacionar, analisar com seus alunos as amplas manifestações da cultura corporal, levando estes à compreensão dos sentidos e significados impregnados nas práticas corporais" (DARIDO; SOUZA JÚNIOR, 2007, p. 14). Logo, a Educação Física na escola deve deixar claro que valoriza as diferentes formas de expressão, não o alto-rendimento, pois "não é porque um aluno não possui habilidade refinada no futebol que ele deve ser tratado de forma inferiorizada nas aulas; muitas vezes esse aluno possui uma maior afinidade com outros componentes da cultura corporal, como as lutas ou a dança, por exemplo" (DARIDO; SOUZA JÚNIOR, 2007, p. 22). Mais do que ensinar esportes e gestos técnicos ou realizar atividades físicas pensando na promoção da saúde, a Educação Física potencializa leituras de mundo pela experimentação das práticas corporais. Afinal, os seres humanos quando brincam, dançam e praticam esportes, se comunicam através de linguagens corporais e seus significados, e por meio de gestos, rituais e corpos expressam intencionalidades, modos de ser, de pensar e de agir, conforme características dos grupos culturais à qual pertencem ou estabelecem vínculos (NEIRA; NUNES, 2009). 


\section{CONSIDERAÇÕES FINAIS}

Em resposta à questão orientadora da pesquisa - o que mobiliza o desinteresse dos estudantes do Ensino Médio pelas experimentações corporais nas aulas de Educação Física? -, entendemos que o desinteresse demonstrado pelos estudantes está condicionado ao descompasso entre o que é planejado e desenvolvido nas aulas e as expectativas e percepções dos estudantes sobre a Educação Física. No bojo desse processo, entendemos que há uma lacuna entre os conteúdos de ensino trabalhados em aula e o cotidiano vivido pelos jovens na contemporaneidade que os leva a não encontrar sentido para se envolverem ativamente nas experimentações corporais, nem participar das discussões em aula.

Com essas considerações, queremos salientar que, de um lado, é fundamental reconhecer os estudantes como protagonistas dos processos educativos e criar estratégias para que participem da seleção e das discussões sobre as práticas corporais. Dialogar, selecionar, experimentar e problematizar as práticas corporais com os estudantes seriam possibilidades de atribuir outros sentidos às aulas. De outro lado, é importante repensar os procedimentos didático-pedagógicos empregados e superar a perspectiva reducionista da Educação Física por outra, que abranja a reflexão crítica da cultura corporal, contemple as experiências e inquietações dos estudantes e, dessa forma, seja capaz de reiterar - ou recuperar - a potencialidade educativa da Educação Física.

Mais do que uma dificuldade a ser enfrentada pelos professores, o desinteresse dos estudantes pelas experimentações corporais também revela que há estudantes do $3^{\circ}$ Ano do Ensino Médio prestes a concluir o processo de escolarização sem compreender por que tiveram aulas de Educação Física na escola. Por isso, em conclusão, destacamos a importância de dialogar com os estudantes do Ensino Médio e escutá-los, bem como desenvolver pesquisas na escola - tarefas que, para nós, são imprescindíveis para legitimar a Educação Física escolar.

\section{REFERÊNCIAS}

ALMEIDA, P. C.; CAUDURO, M. T. O desinteresse pela Educação Física no ensino médio. EFDeportes, Revista Digital. Buenos Aires, a. 20, n. 214, março/2016. Disponível em http:/ / www.efdeportes.com/efd106/o-desinteresse-pela-educacaofisica-no-ensino-medio.htm. Acesso em: 25/10/2016.

BETTI, M.; ZULIANI, L. R. Educação física escolar: uma proposta de diretrizes pedagógicas. Revista Mackenzie de Educação Física e Esporte, São Paulo, v. 1, n. 1, p. 73-82, jan./dez. 2002.

BOGDAN, R. C; BILKLEN, S. K. Investigação qualitativa em educação: uma introdução a teoria e aos métodos. Porto: Porto, 1994. 
CELANTE, A. R. Educação física e cultura corporal: uma experiência de intervenção pedagógica no Ensino Médio. 174 f. Dissertação (Mestrado). Faculdade de Educação Física, Universidade Estadual de Campinas, Campinas, SP, 2000.

CHEMIN, B. F. Manual da Univates para trabalhos acadêmicos: planejamento, elaboração e apresentação. 2. ed. Lajeado: Univates, 2012.

CHICATI, K. C. Motivação nas aulas de Educação Física no Ensino Médio. Revista da Educação Física - UEM, Maringá, v.11, n.1, p. 97-105, 2000.

DARIDO, S. C.; SOUZA JÚNIOR, O. M. de. Para ensinar educação física:

Possibilidades de intervenção da escola. Campinas: Papirus, 2007.

FERREIRA, M. L. S.; GRAEBNER, L.; MATIAS, T. S. Percepção de alunos sobre as aulas de educação física no ensino médio. Pensar a Prática, Goiânia, v. 17, n. 3, p. 734750, jul./set. 2014.

LIMA FILHO, P. S. R. Motivos que levam a evasão nas aulas de Educação Física no ensino médio. EFDeportes, Revista Digital Buenos Aires, Ano 20, № 214, Março/2016. Disponível em <http:/ / www.efdeportes.com/efd214/evasao-nas-aulas-de-educacaofisica.htm>. Acesso em: 25 de outubro de 2019.

MATTOS, M. G.; NEIRA, M. G. Educação física na adolescência: construindo o conhecimento na escola. São Paulo: Phorte, 2000.

MINAYO, M. C. S. O desafio do conhecimento: pesquisa qualitativa em saúde. São Paulo: HUCITEC, 2007.

MORAES, R. Mergulhos discursivos: análise textual qualitativa entendida como processo integrado de aprender, comunicar e interferir em discursos. In: GALIAZZI, Maria do Carmo; FREITAS, José Vicente. Metodologias emergentes de pesquisa em educação ambiental. Ijuí: Unijuí, 2007, p. 85-114.

NEIRA, M. G. Ensino de educação física. São Paulo: Cengage Learning, 2010.

NEIRA, M. G.; NUNES, M. L. F. Praticando estudos culturais na educação física. São Caetano do Sul: Yendis, 2009.

SOARES, C. L.; TAFFAREL, C. N. Z.; VARJAL, E.; CASTELLANI FILHO, L.; ESCOBAR, M. O.; BRACHT, V. Metodologia do Ensino de educação física. 2.ed. São Paulo: Cortez, 2012.

SOUZA, A. S. Educação Física e conhecimentos no Ensino Médio: tensões do cotidiano escolar. In: CORREIA, W. R.; CARREIRA FILHO, D. Educação Física Escolar: docência e cotidiano. Curitiba: Editora CRV, 2010. p. 177-188.

TRIVIÑOS, A. N. S. Introdução à pesquisa em ciências sociais: a pesquisa qualitativa em educação. São Paulo: Atlas, 1987. 
ZILBERSTEIN, J. "Parece ser": uma etnografia sobre a cultura juvenil, a Educação Física e a escola pública. 139f. Dissertação (Mestrado). Universidade Federal do Rio Grande do Sul, Escola de Educação Física, Fisioterapia e Dança, Programa de PósGraduação em Ciências do Movimento Humano, Porto Alegre, RS, 2016. 